\title{
Risk Mitigation for Removal of Pesticide Residues in Curry Leaf for Food Safety
}

\author{
Swarupa S, Shashi Vemuri, V.Venkateswar Reddy ${ }^{1}$, K.Kavitha \\ All India Network Project on Pesticide Residues \\ Prof.Jayashankar Telangana State Agricultural University, Rajendranagar, Hyderabad-500030, \\ ${ }^{1}$ JNTU, Telangana , India
}

\begin{abstract}
The increased consumer awareness and legal issues on food safety, with special reference to insecticide residues in foods, led us to attempt for cheap and effective methods for removal of pesticide residues to address the issues of consumer and food safety, as the farmers are not following the Good Agricultural Practices i.e pre-harvest intervals. The most commonly used pesticides such as dimethoate, quinalphos, acephate, imidacloprid and bifenthrin were sprayed at recommended doses at vegetative stage, samples were collected at 2 hours after treatment to quantify the deposits. The samples were subjected to various household treatments each in three replications, and analysed for residues using validated QuEChERS method, so as to estimate the \% removal and their effectiveness. Out of all treatments, respectively, and is the best household method for removal of pesticide residues, and also the method is effective in reducing the residues below MRL (Maximum Residue Limits).
\end{abstract}

Keywords-Pesticide Residues, curryleaf, Food Safety, Risk Mitigation, MRL.

\section{INTRODUCTION}

Murraya koenigii L. (curry leaf) belonging to family Rutaceae is a leafy spice characterizing authentic AsianIndian cuisine and it is used in small quantities for its distinct aroma as well as for preservation purposes., Curry leaf oil an volatile oil, produced from the plant has uses in the soap industry. (Salikutty and Peter., 2008). Recent studies have shown that carbazole alkaloids have several biological activities such as anti carcinogenic effects in dimethyl hydrazine (DMH) treated rats (Khanum et al., 2000), anti platelet activity and vaso relaxing effects ( $\mathrm{Wu}$ et al., 1998). Chevalier (1996) also reported that curry leaf has medicinal value as traditionally used in Eastern Asia. Interest in greater use of curry leaf has been stimulated since its high antioxidant potency was reported and this antioxidant activity is attributed due to maha nimbine, murrayanol and mahanine from M. koenigii (Tachibana etal.,2003; Ningappa et al.,2008). Chowdhary et al.(2001) reported that these alkaloids have antimicrobial activity against gram positive and negative bacteria, and fungi. Lee et al. (2002) noted that enrichment of phenolic compounds within the plant extract is correlated with their enhanced antioxidant activity, It is reported to have antioxidant, anti-diabetic, anti carcinogenic,anti dysenteric stimulant, hypo glycaemic and antimicrobial activities (Khanum et al, 2000). Biologically active carbazole alkaloids are reported to have anti microbial properties (Ramsewak et al ,1999). Curry leaves have been reported to contain tocopherol, b-carotene,lutein and alkaloids (Khanum et al., 2000). But it is observed that curry leaves have received red alert message from the European Union, who are the major importers, where the pesticide residue limits were found much beyond the permissible levels. This created a panic among the mass as curry leaves constitute a major spice exported from India. Uncontrolled use of pesticides and non-adoption of safe waiting periods has led to pesticide accumulation in curry leaf crop. The residues being persistent in nature infiltrate crops, contaminate water, pollute complete food chain and enter our body through diet.. Since farmers are using lot of pesticides and the persistence and dissipation of these insecticides is not known on curryleaf, the present study is proposed to study the dissipation commonly pesticides, so as to recommend the safe waiting periods based on the Maximum Residue Limits (MRLs) calculated, as it helps in recommending risk mitigation protocols for food safety.Maximum Residue Limits (MRLs) are set by Codex Alimentarius Commission (CAC) at international level and as on date, no MRLs are set for any pesticides on curryleaf, and by Food Safety and Standards Authority of India (FSSAI) of Ministry of Health and Family Welfare, Government of India, as per Food Safety and Standards Act, 2006 (Food Safety and Standards Regulation, 2011) at national level based on the Good Agricultural Practices. The major insect pest of curry leaf for which farmers apply insecticides at almost weekly interval, and hence the risk of pesticide residues in foods need to be addressed as per FSSAI (Food Safety and Standards Authority of India) for the protection of consumer health and interests. In this context, household risk mitigation methods for removal of pesticide residues in curry leaf are to be recommended based on the scientific evaluation, as the food habits are changing enormously. 


\section{MATERIALS AND METHODS}

For the Decontamination of pesticide residues of commonly detected pesticides a field experiment was conducted utilizing dimethoate, quinalphos,acephate,imidacloprid and bifenthrin twice,first at Vegetative stage and 10 days later. Zero day samples were collected for estimation of deposits of pesticide within 2 hours of last spray.

Evaluation of decontamination methods for removal of pesticide residues:

The zero day samples which are free from pests and damage were collected from various treatments separately in large quantities and made into thirteen sets, each in four replications. One set of the sample from each treatment (in four replications) was analyzed for deposits of the pesticide. The remaining sets of samples of zero day from each treatment samples were subjected to various decontamination methods separately and the residues were calculated to know the efficiency of the various decontamination methods in the removal of pesticide residues from the curry leaf samples. The decontamination methods used in the study / risk mitigation methods are given (Table 1 ).

Per cent removal of pesticide:

Initial deposit - Residues after treatment

Per cent removal $=$

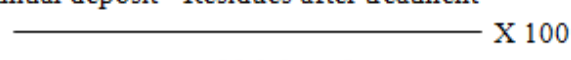

Sample extraction procedure

Initial deposit

After spray of pesticide, about $5 \mathrm{kgs}$ of curryleaf were collected randomly in polythene bags from each plot to avoid cross contamination. Each lot from treatment plot was divided in to 13 sub-lots, where one lot was analysed for initial deposits, and remaining lots were subjected to various rick mitigation methods prior to analysis. All samples were replicated thrice. The decontamination methods used in the study are presented in Table 1. curry leaf samples were collected from the fields sprayed with insecticides and brought to the laboratory and analyzed for pesticide residues following the AOAC official method 2007.01(QuEChERS)after validation of the method in the laboratory. Each sample was homogenized separately with robot coupe blixer and homogenized 15 $\pm 0.1 \mathrm{~g}$ sample was taken in $50 \mathrm{ml}$ centrifuge tube and $30 \pm 0.1 \mathrm{ml}$ acetonitrile was added to sample tube. The sample was homogenized at 14000-15000 rpm for 2-3 min using Heidolph silent crusher. $3 \pm 0.1$ g sodium chloride was added to sample, mixed thoroughly by shaking gently followed by centrifugation for $3 \mathrm{~min}$ at 2500-3000 rpm to separate the organic layer. The top organic layer of about $16 \mathrm{ml}$ was taken into the $50 \mathrm{ml}$ centrifuge tube and added with $9 \pm 0.1 \mathrm{~g}$ anhydrous sodium sulphate to remove the moisture content. $8 \mathrm{ml}$ of extract was taken in to $15 \mathrm{ml}$ tube, containing $0.4 \pm 0.01 \mathrm{~g}$ PSA sorbent(for dispersive solid phase d-SPE cleanup), $1.2 \pm 0.01 \mathrm{~g}$ anhydrous magnesium sulphate and $0.05 \mathrm{~g}$ of $\mathrm{GCB}$ (Graphatised Carbon Black). The sample tube was vortexed for $30 \mathrm{sec}$ then followed by centrifugation for $5 \mathrm{~min}$ at 2500-3000rpm. The extract of about $1 \mathrm{ml}(0.5 \mathrm{~g}$ sample) was taken for analysis on LCMS/MS under standard operational conditions(Table2).

Table.2: LCMS/MS Instrument parameters

\begin{tabular}{|c|c|c|c|}
\hline LC-MS/MS & \multicolumn{3}{|c|}{ SHIMADZU LC-MS/MS - 8040.} \\
\hline Detector & \multicolumn{3}{|c|}{ Mass Spectrophotometer } \\
\hline Column & \multicolumn{3}{|c|}{ 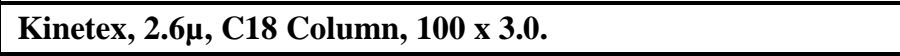 } \\
\hline Column oven temperature & \multicolumn{3}{|l|}{$40^{\circ} \mathrm{C}$} \\
\hline Retention time & \multicolumn{3}{|c|}{ dimethoate, quinalphos, acephate, imidacloprid and bifenthrin } \\
\hline Nebulizing gas & \multicolumn{3}{|c|}{ Nitrogen } \\
\hline Nebulizing gas flow & \multicolumn{3}{|c|}{2.0 litres/min } \\
\hline Pump mode/ flow & \multicolumn{3}{|c|}{ Gradient $/ 0.4 \mathrm{ml} / \mathrm{min}$} \\
\hline LC Solvents & \multicolumn{3}{|c|}{$\begin{array}{l}\text { A: Ammonium Formate In Water (10Mm) } \\
\text { B: Ammonium Formate In Methanol (10Mm) }\end{array}$} \\
\hline LC programme & $\begin{array}{r}\text { Time } \\
0.01 \\
2.00 \\
7.00 \\
9.00 \\
14.00 \\
17.00 \\
19.00 \\
21.00 \\
24.00\end{array}$ & $\begin{array}{c}\text { A Conc } \\
\mathbf{6 5} \\
\mathbf{6 5} \\
\mathbf{4 0} \\
\mathbf{4 0} \\
\mathbf{0 5} \\
\mathbf{1 5} \\
\mathbf{3 0} \\
\mathbf{6 5} \\
\mathbf{6 5}\end{array}$ & $\begin{array}{c}\text { B Conc } \\
\mathbf{3 5} \\
\mathbf{3 5} \\
\mathbf{6 0} \\
\mathbf{6 0} \\
\mathbf{9 5} \\
\mathbf{8 5} \\
\mathbf{7 0} \\
\mathbf{3 5} \\
\mathbf{3 5}\end{array}$ \\
\hline Total Time Programme & $24 \min$ & & \\
\hline
\end{tabular}




\section{RESULTS AND DISCUSSION}

The residues of dimethoate, quinalphos, acephate, imidacloprid and bifenthrin in curryleaf samples have got substantial reduction by different house hold processing methods. The reduction percentage and residue levels are presented in Table 3 and fig $1-6$.

Evaluation of decontamination methods for removal of pesticide residues:

Curry leaf is an important export commodity from India, rich in vitamin A, calcium, carbazole alkaloids and volatile oils. However, along with life-saving components, they have turned into a major source of lifetaking poisonous substances called pesticides and their residues into the human body. Indiscriminate use of pesticides particularly at vegetative stage and nonadoption of safe waiting period leads to accumulation of pesticide residues in consumable parts. Scientists and food processors have long been interested in the effect of processing on pesticide residues in food commodities. The extent to which pesticide residues are removed by processing depends on a variety of factors, such as chemical properties of the pesticides, the nature of food commodity, the processing step and the length of time the compound has been in contact with the food (Farris et al., 1992., Holland et al., 1994 and Kumar et al., 2010). In a developing country like India, dissipation techniques at the household level can serve as an effective tool in reducing risk related to dietary exposure to residues and henceforth controlling pesticide related adversities. Washing is the most common form of processing which is a preliminary step in both household and commercial preparation. Loosely held residues of several pesticides are removed with reasonable efficiency by varied types of washing processes (Street, 1969). Several studies have examined the effects of washing solutions on removing pesticide residues from various food commodities as follows

\section{Dimethoate}

Dimethoate is an organophosphorus insecticide with excellent systemic, contact and acaricidal action. Dipping in $2 \%$ salt solution for 10 min followed by tap water wash for $30 \mathrm{sec}$ was found to be most effective $(93.33 \%$ removed) than other treatments. The percentage removal of dimethoate residues due to various decontamination treatments in descending order are tap water wash for 30 sec. Cooking $(93.33 \%)$, formula $1(53.23 \%)>0.1 \%$ baking soda solution(48.07\%) > frying (47.75\%) tamarind water $(42.15 \%)>$ bio wash $(37.00 \%)>$ drying $(35.21 \%)>$ acetic acid $(28.63 \%)>$ butter milk $(26.27$ $\%)>$ tap water $(26.01 \%)>$ lemon water $(20.78 \%)>2 \%$ salt solution (14.79\%).Based on the percentage removal of residues, it was statistically proved that there is significant difference in the efficiency of decontaminating solutions in removing dimethoate residues. Percentage removal of dimethoate residues from various decontamination methods is depicted in Fig.1.

\section{Quinalphos}

Various decontamination methods were evaluated in order to know their efficiency in removing Quinalphos residues from curry leaf. Results revealed that all the treatment solutions significantly differed among each other in their efficiency in removing Quinalphos residues. Drying under sunlight was found to be most effective (73.97\%) than other treatments. Next promising treatment was cooking in pressure cooker for $15 \mathrm{~min}$ followed by $0.1 \%$ baking soda solution $(55.60 \%)>$ formula $1(39.27 \%)>$ tamarind water $(38.96 \%)>$ bio wash $(30.94 \%)>$ frying $(28.46 \%)>$ butter milk $(25.11 \%)>$ tap water $(11.93 \%)$ $>$ lemon water $(9.10 \%)>$ acetic acid $(8.40 \%)>2 \%$ salt solution $(3.53 \%)$ were also found to remove significant amount of residues from curry leaf samples.Percentage removal of Quinalphos residues from various decontamination methods is depicted in Fig. 2.

\section{Acephate}

Curry leaves sprayed with recommended dose of acephate were collected 2 hours after spraying and subjected to various decontamination methods. Among the different treatments employed, pressure cooking for 15 min was found to be more effective $(80.91 \%)$ than other treatments. Tamarind water $(58.74 \%)$ was found to be next promising treatment, followed by frying $(54.97 \%)>$ acetic acid $(52.84 \%)>$ bio wash $(46.48 \%)>$ butter milk $(46.19 \%)>$ tap water $(45.04 \%)>2 \%$ salt solution $(30.57 \%) 0.1 \%$ baking soda solution $(30.25 \%)>$ lemon water $(25.27 \%)>$ formula $1(23.51 \%)>$ drying $(12.08$ $\%)$.Percentage removal of acephate residues from various decontamination methods is depicted in Fig. 3.

\section{Imidacloprid}

Imidacloprid residues in curry leaf was removed significantly when subjected to different decontamination solutions at 2 hours after spraying. Results revealed that pressure cooking for 15 min was found to be most effective than other treatments. In this treatment residues were reduced up to $79.89 \%$. Next promising treatment was frying $(56.83 \%)$ followed by tamarind water $(49.44$ $\%)>$ bio wash $(41.92 \%)>$ butter milk $(39.51 \%)>$ formula $1(37.66 \%)>$ tap water $(33.17 \%)>$ lemon water $(32.01 \%)>0.1 \%$ baking soda solution $(31.78 \%)>$ acetic acid $(29.04 \%)>$ drying $(16.34 \%)>2 \%$ salt solution $(10.40 \%)$. Percentage removal of imidacloprid residues from various decontamination methods is depicted in Fig. 4.

\section{Bifenthrin}

The percentage removal of bifenthrin residues in curry leaf when subjected to different decontamination solutions at 2 hours after spraying showed that dipping in lemon water for 10 min followed by tap water wash for $30 \mathrm{sec}$ was found to be most effective removing $53.29 \%$ 
residues, than other treatments. The next promising treatment was drying $(46.97 \%)>$ followed by tamarind water $(45.88 \%)>$ butter milk $(42.54 \%)>$ bio wash $(31.55 \%)>$ acetic acid $(31.20 \%)>2 \%$ salt solution $(28.52 \%)>0.1 \%$ baking soda $\operatorname{solution}(27.94 \%)>$ formula $1(20.07 \%)>$ Cooking $(19.70 \%)>$ frying $(15.50$ $\%)>$ tap water $(4.35 \%)$. Based on the percentage removal of residues, it was statistically proved that there is significant difference in the efficiency of decontaminating solutions in removing residues of above mentioned pesticides. Percentage removal of bifenthrin residues from various decontamination methods is depicted in Fig.5. In the present study, veggy wash a formulation prepared by AINP on Pesticide Residues proved to be the most efficient in removing various pesticides.

The next promising treatment was dipping in $4 \%$ acetic acid solution for $10 \mathrm{~min}$ followed by tap water wash for $30 \mathrm{sec}$. Similar results were reported by Radwan et al. (2004) who reported that washing of hot pepper, sweet pepper and brinjal with $2 \%$ acetic acid removed pirimophos-methyl residues by $76.61,95.74$ and $94.58 \%$. Similarly, Zhang et al. (2006) found that 79.8, 65.8, 74.0 and $75.0 \%$ residues of chlorpyrifos, $p, p$-DDT, cypermethrin and chlorothalonil were removed by washing cabbage with $10 \%$ acetic acid solution for 20 min, respectively. $2 \%$ salt solution was found to be third best treatment .Washing of curry leaf with $10 \%$ salt solution removed 90.80 and $82.40 \%$ of dimethoate and profenophos residues (Abou-Arab,1999). Dipping in $0.1 \%$ baking soda $\left(\mathrm{NaHCo}_{3}\right)$ solution for $10 \mathrm{~min}$ followed by tap water wash was the $4^{\text {th }}$ best treatment in removing residues from curry leaves. The results are in line with the findings of Liang et al. (2012) who reported that washing of cucumber with $2 \% \mathrm{NaHCO}_{3}$ was efficient enough to remove the trichlorfon, dimethoate, dichlorovos, fenitrothian and chlorpyrifos residues by 73.20, 58.70, $96.40,51.10$ and $77.80 \%$. Similarly the results are in agreement with Satpathy (2012) who found that curry leaf fruits washed with $0.1 \% \quad \mathrm{NaHCO}_{3}$ solution removed residues of parathion, methyl parathion, malathion, fenitrothion, formothion and chlorpyriphos by 73.10 , $77.40,86.80,57.00,86.40$ and $87.20 \%$ respectively. Washing of chinese kale with $0.1 \% \mathrm{NaHCO}_{3}$ solution removed methomyl and carbaryl residues by 43.19 and $91.24 \%$ respectively (Klinhom, 2008). Tap water wash was the least effective treatment and the findings of present investigations are in agreement with the findings of Abou-Arab (1999) who reported that washing of curry leaf with water removed dimethoate and profenophos residues up to 18.80 and $22.17 \%$ respectively. Similarly tap water wash for $10 \mathrm{~min}$ removed trichlorfon, dimethoate, dichlorovos, fenitrothian and chlorpyrifos residues by $36.60,21.70,22.60,22.20$ and $59.20 \%$ in cucumber respectively (Liang et al., 2012).
Based on the percentage removal of residues, it was statistically proved that there is significant difference in the efficiency of decontaminating methods in removing residues of above mentioned pesticides. Per cent removal of pesticide residues from curry leaf by various decontamination methods is depicted in fig-1-6. Scientists and food processors have long been interested in the effect of processing on pesticide residues in food commodities. The extent to which pesticide residues are removed by processing depends on a variety of factors, such as chemical properties of the pesticides, the nature of food commodity, the processing step and the length of time the compound has been in contact with the food (Farris et al., 1992., Holland et al., 1994 and Kumar et al., 2010).In a developing country like India, dissipation techniques at the household level can serve as an effective tool in reducing risk related to dietary exposure to residues and henceforth controlling pesticide related adversities. Washing is the most common form of processing which is a preliminary step in both household and commercial preparation. Loosely held residues of several pesticides are removed with reasonable efficiency by varied types of washing processes (Street, 1969). Several studies have examined the effects of washing solutions on removing pesticide residues from various food commodities as follows. To minimize dietary exposure to pesticides, it is pertinent to explore strategies that effectively help in reducing the residue content at individual level. Twelve simple, labour-less and cost effective unit operations were imparted to curry leaf samples for reducing dietary consumption of pesticide residues which can be even followed in poor populace. Out of all treatments imparted each pesticide has its own treatment of reduction

\section{REFERENCES}

[1] Chowdhury,B.K.,Jha,S.,Bhattacharyya, P.and Mukherjee, J.(2001). Two new carbazole alkaloids from Murraya koenigii. Indian Journal of Chemistry 40: 490-494.

[2] Farris, G. A., Cabras, P and Spanedda, L. 1992. Pesticide residues in food processing. Italian Journal of Food Science. 4: 149-169.

[3] Holland, P. T., Hamilton, D., Ohlin, B and Skidmore, M. W. 1994. Effects of storage and processing on pesticide residues in plant products. Pure and Applied Chemistry. 66: 335-356.

[4] Khanum, Farhath.,Anilaumar, K. R., Sudarshana Krishna, K. R., Viswanathan,K. R.,\& Santhanam, K.(2000). Anticarcinogenic effects of curry leaves in dimethylhydrazine- treated rats. Plant Foods for Human Nutrition, 55, 347-355.

[5] Klinhom, P., Halee, A and Methawiwat, S. 2008. 
The effectiveness of household chemicals in residue removal of methomyl and carbaryl pesticides on chinese kale. Kasetsart Journal Natural Science. 42: 136-143.

[6] Kumar, K. P., Reddy, D. J., Reddy, K. N., Babu, T. R and Narendhranath, V. V. 2000. Dissipation and decontamination of triazophos and acephate residues in chilli (Capsicum annum). Pesticide Research Journal. 12 (1): 26-29.

[7] Lee, J.C., Kim, H.R., Kim, J. and Jang, Y. S. 2002. Antioxidant activity of ethanol extract of the stem Of Opuntia ficus-indica var. saboten. Journal of Agriculture and Food Chemistry 50: 6490-6496.

[8] Liang, Y., Wang, W., Shen, Y., Liu, Y and Lui, X. J. 2012. Effects of home preparation on organophosphorus pesticide residues in raw cucumber. Food Chemistry. 133: 636- 640.

[9] Ningappa, M.B., Dinesha, R., and Srinivas, L. 2008. Antioxidant and free radical scavenging activities of polyphenol-enriched curry leaf (Murraya koenigii L.) extracts. Food Chemistry 106: 720-728.

[10] Radwan, M. A., Shiboob, M. M., Elamayem, A and Aal, A. A. 2004. Pirimiphos-methyl residues in some field grown vegetables and removal using various washing solutions and kitchen processing. International Journal of Agriculture and biology. 6(6): 1026-1029.

[11]Ramsewak,R.S.,Nair, ～M. G.,Strasburg,G.M.,De
Witt, D. L. and Nitiss, J. L. (1999). Biologically active carbazole alkaloids from Murraya koenigii. Journal of Agricultural and Food Chemistry,47,444- 447.

[12] Randhawa, M. A., Anjum, F. M., Randhawa, M. S., Ahmed, A., Farooq, U., Abrar, M and Randhawa, M. A. 2008. Dissipation of deltamethrin on supervised vegetables and removal of its residue by household processing. Journal of Chemical Society of Pakisthan. 30 (2): 227-231.

[13] Salikutty Joseph and K. V. Peter, Curry leaf ( Murrayakoenigii ), perennial, nutritious, leafy vegetable Economic Botany (2008) 39 (1): 68-73.

[14] Satpathy, G. 2012. Removal of organophosphorus pesticide residues from vegetables using washing solutions and boiling. Journal of Agricultural sciences. 4(2): 69-78.

[15] Street, J. C. 1969. Methods of removal of pesticide residues. Canadian Medical Association Journal. 100: 154-160.

[16] Tachibana, Y., Kikuzaki, H., Lajis, N.H. and Nakatani, N. (2003). Comparison of antioxidative properties of carbazole alkaloids from Murraya koenigii leaves. Journal of Agriculture and Food Chemistry 51: 6461-6467.

[17]Zhang, Z. Y., Liu, X. J and Hong, X. Y. 2006.Effects of home preparation on pesticide residues in cabbage. Food Control. 18: 1484-1487.

Table.3: Effectiveness of various decontamination methods

\begin{tabular}{|c|c|c|c|c|c|}
\hline \multirow{3}{*}{$\begin{array}{l}\text { Decontamination } \\
\text { methods }\end{array}$} & \multicolumn{5}{|c|}{ Mean per cent removal of insecticides $(\%) \pm$ SD } \\
\hline & \multicolumn{5}{|l|}{ Insecticides } \\
\hline & Dimethoate & Quinalphos & Acephate & Imidacloprid & Bifenthrin \\
\hline $2 \%$ Salt solution & $14.79 \pm 3.14$ & $3.53 \pm 0.25$ & $30.57 \pm 0.47$ & $10.40 \pm 11.46$ & $19.70 \pm 1.72$ \\
\hline Acetic acid & $28.63 \pm 0.48$ & $8.40 \pm 1.40$ & $52.84 \pm 2.50$ & $29.04 \pm 1.26$ & $15.50 \pm 0.17$ \\
\hline Bio wash & $37.00 \pm 0.49$ & $30.94 \pm 6.16$ & $46.48 \pm 1.06$ & $41.92 \pm 2.42$ & $45.88 \pm 1.91$ \\
\hline Butter milk & $26.27 \pm 0.61$ & $25.11 \pm 0.85$ & $46.19 \pm 0.49$ & $39.51 \pm 0.83$ & $31.55 \pm 0.89$ \\
\hline Cooking & $93.33 \pm 0.04$ & $64.79 \pm 0.74$ & $80.91 \pm 0.28$ & $79.89 \pm 0.40$ & $42.54 \pm 0.26$ \\
\hline Drying & $35.21 \pm 0.35$ & $73.97 \pm 1.49$ & $12.08 \pm 2.58$ & $16.34 \pm 0.44$ & $20.07 \pm 0.06$ \\
\hline Formula1 & $53.23 \pm 0.57$ & $39.27 \pm 0.13$ & $23.51 \pm 0.28$ & $37.66 \pm 3.15$ & $53.29 \pm 0.84$ \\
\hline Frying & $47.75 \pm 0.88$ & $28.46 \pm 0.57$ & $54.97 \pm 0.22$ & $56.83 \pm 0.74$ & $4.35 \pm 0.92$ \\
\hline Lemon water & $20.78 \pm 0.29$ & $9.10 \pm 0.31$ & $25.27 \pm 0.47$ & $32.01 \pm 0.22$ & $27.94 \pm 6.13$ \\
\hline Sodium bicarbonate & $48.07 \pm 0.21$ & $55.60 \pm 0.15$ & $30.25 \pm 0.49$ & $31.78 \pm 0.52$ & $31.20 \pm 3.82$ \\
\hline Tamarind water & $42.15 \pm 0.33$ & $38.96 \pm 0.24$ & $58.74 \pm 0.73$ & $49.42 \pm 0.12$ & $46.97 \pm 1.50$ \\
\hline Tap water & $26.01 \pm 0.29$ & $11.93 \pm 1.26$ & $45.04 \pm 0.61$ & $33.17 \pm 0.29$ & $28.52 \pm 1.62$ \\
\hline
\end{tabular}


Table 1.4: Decontamination methods used in the study or risk mitigation methods

\begin{tabular}{|c|c|c|c|}
\hline $\begin{array}{l}\text { Treatment } \\
\text { Number }\end{array}$ & Treatment Name & Method & \\
\hline $\mathbf{T}_{1}$ & Tap water & Four litres of tap water was taken & \multirow{9}{*}{$\begin{array}{l}\text { In the plastic tub of } 7 \\
\text { litres capacity } 2 \mathrm{~kg} \text { of } \\
\text { curry leaves were dipped } \\
\text { for } 10 \text { min, followed by } \\
\text { washing with tap water } \\
\text { for } 30 \text { sec. Further the } \\
\text { leaves were kept for air } \\
\text { drying on tissue paper for } \\
5 \text { min, followed by } \\
\text { analysis. }\end{array}$} \\
\hline $\mathbf{T}_{2}$ & Tamarind solution & $80 \mathrm{~g}$ of tamarind was added to 4 litres of water & \\
\hline $\mathbf{T}_{3}$ & Lemon water & Juice of 4 lemons was added to 4 litres of water & \\
\hline $\mathbf{T}_{4}$ & Salt solution & $\begin{array}{l}\text { Four litres of } 2 \text { per cent salt solution was } \\
\text { prepared by mixing } 80 \mathrm{~g} \text { of table salt in } 4 \text { litres } \\
\text { of water }\end{array}$ & \\
\hline $\mathbf{T}_{5}$ & Butter milk & $\begin{array}{l}\text { Four litres of butter milk was prepared by mixing } \\
80 \mathrm{~g} \text { of curd in } 4 \text { litres of water }\end{array}$ & \\
\hline $\mathbf{T}_{6}$ & Bio wash & $\begin{array}{l}\text { Four litres of bio wash was prepared by mixing } 8 \\
\text { ml of commercial formula bio wash to } 4 \text { litres of } \\
\text { water }\end{array}$ & \\
\hline $\mathbf{T}_{7}$ & Acetic acid & $\begin{array}{l}\text { Four litres of } 4 \text { per cent acetic acid solution was } \\
\text { prepared by mixing } 160 \mathrm{ml} \text { of } 100 \text { per cent } \\
\text { glacial acetic acid in } 4 \text { litres of water }\end{array}$ & \\
\hline $\mathbf{T}_{8}$ & Baking soda $\left(\mathrm{NaHCO}_{3}\right)$ & $\begin{array}{l}\text { Four litres of } 0.1 \text { per cent baking soda solution } \\
\text { was prepared by mixing } 4 \mathrm{~g} \text { of baking soda in } 4 \\
\text { llitres of water }\end{array}$ & \\
\hline $\mathbf{T}_{9}$ & $\begin{array}{ll}\text { Formula } 1 & (4 \% \text { Acetic acid }+ \\
0.1 \% \mathrm{NaHCO}_{3}+ & \left.1 \text { Lemon }^{-1}\right)\end{array}$ & $\begin{array}{l}\text { Four litres of formula } 1 \text { was prepared by mixing } \\
160 \mathrm{ml} \text { of acetic acid, } 4 \mathrm{~g} \text { of sodium bicarbonate } \\
\text { and lemon juice of } 4 \text { lemons added to } 4 \text { litres of } \\
\text { water }\end{array}$ & \\
\hline $\mathbf{T}_{10}$ & Cooking & $\begin{array}{l}2 \mathrm{~kg} \text { of curry leaf sample was cooked in pressure } \\
\text { cooker for } 5 \mathrm{~min} \text {, further the leaves were kept for } \\
\text { air drying on tissue paper for } 5 \mathrm{~min}\end{array}$ & \multirow{3}{*}{ followed by analysis } \\
\hline $\mathbf{T}_{11}$ & Frying & $\begin{array}{l}2 \mathrm{~kg} \text { of curry leaf sample was fried in oil by } \\
\text { repeated stirring until they become brittle by } \\
\text { loosing entire moisture approximately for } 5 \mathrm{~min}\end{array}$ & \\
\hline $\mathbf{T}_{12}$ & Drying & $\begin{array}{l}2 \mathrm{~kg} \text { of curry leaf sample spread over on a tissue } \\
\text { paper and shade dried for approximately } 5 \text { days } \\
\text { until entire moisture was lost in leaves }\end{array}$ & \\
\hline
\end{tabular}




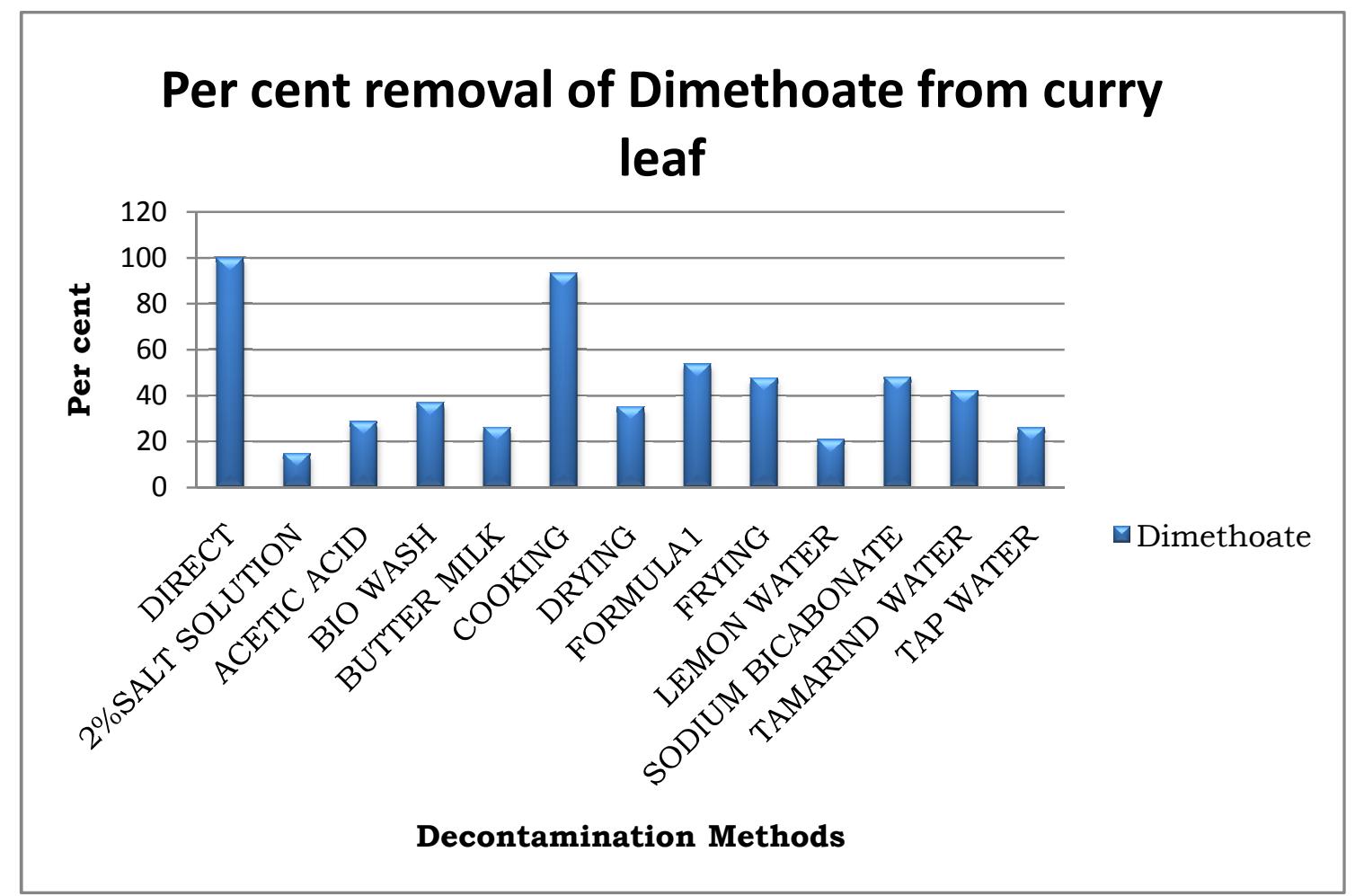

Fig. 1: Per cent removal of dimethoate residues from curry leaf by various decontamination methods

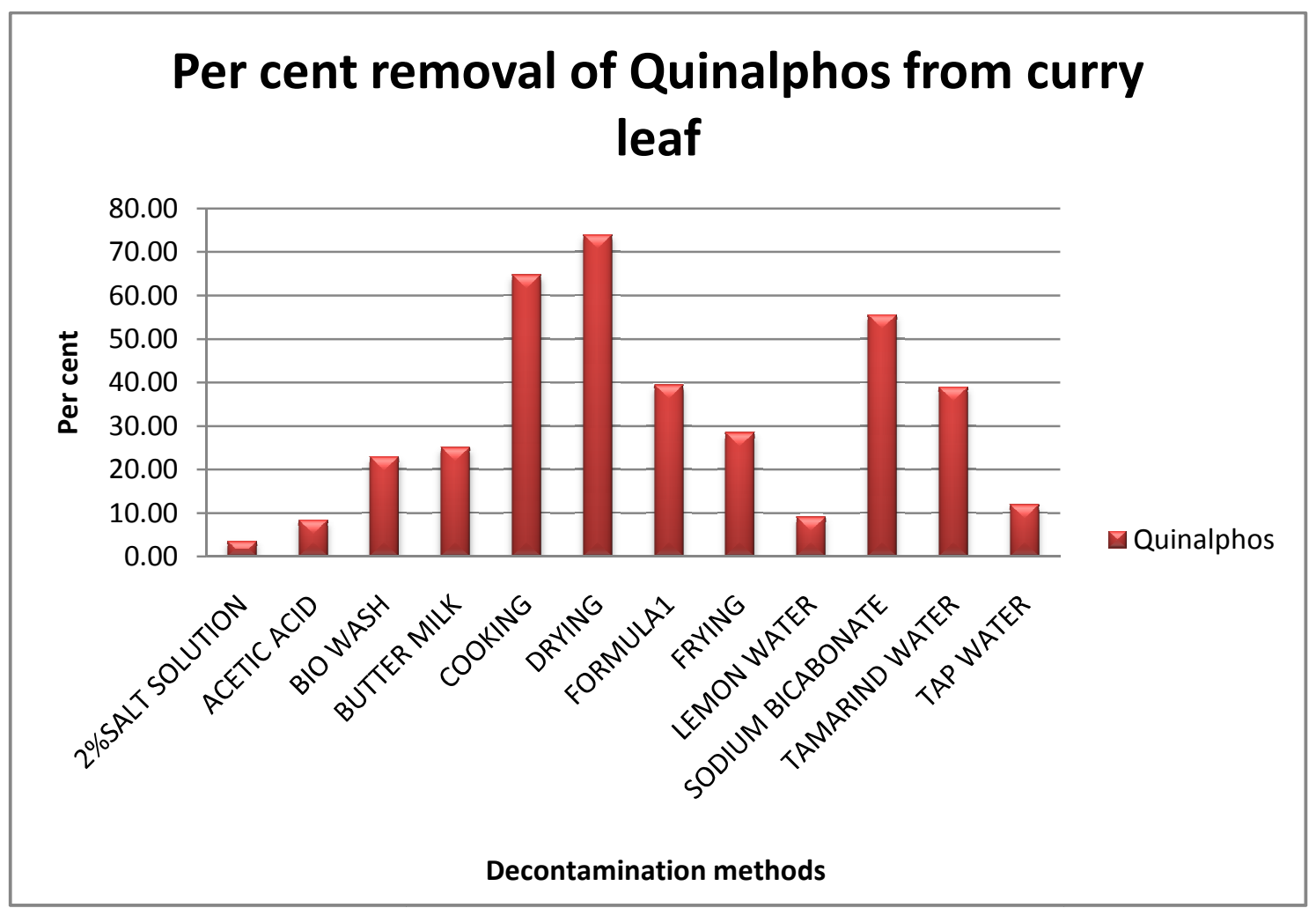

Fig. 2: Per cent removal of quinalphos residues from curry leaf by various decontamination methods 


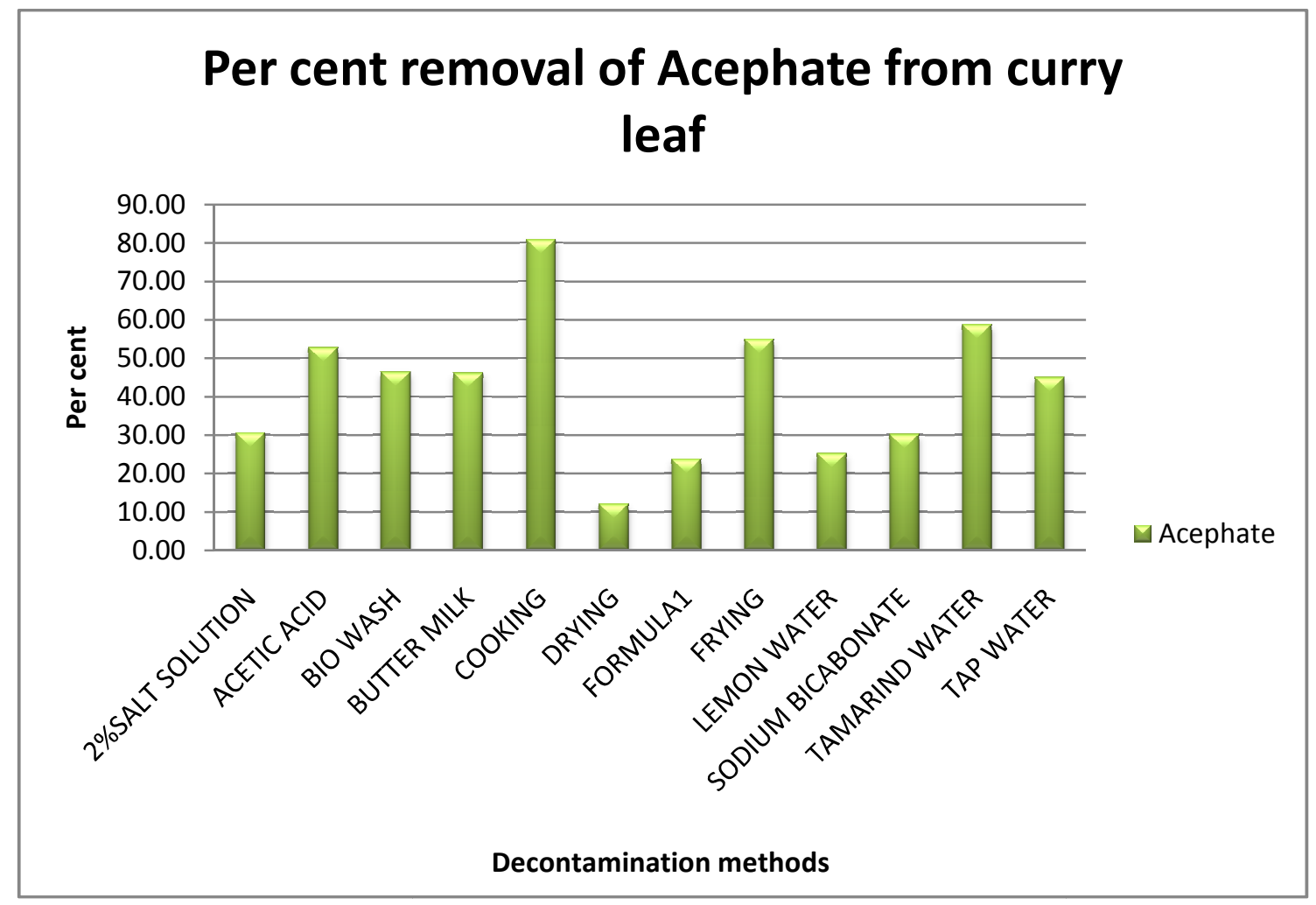

Fig. 3: Per cent removal of acephate residues from curry leaf by various decontamination methods

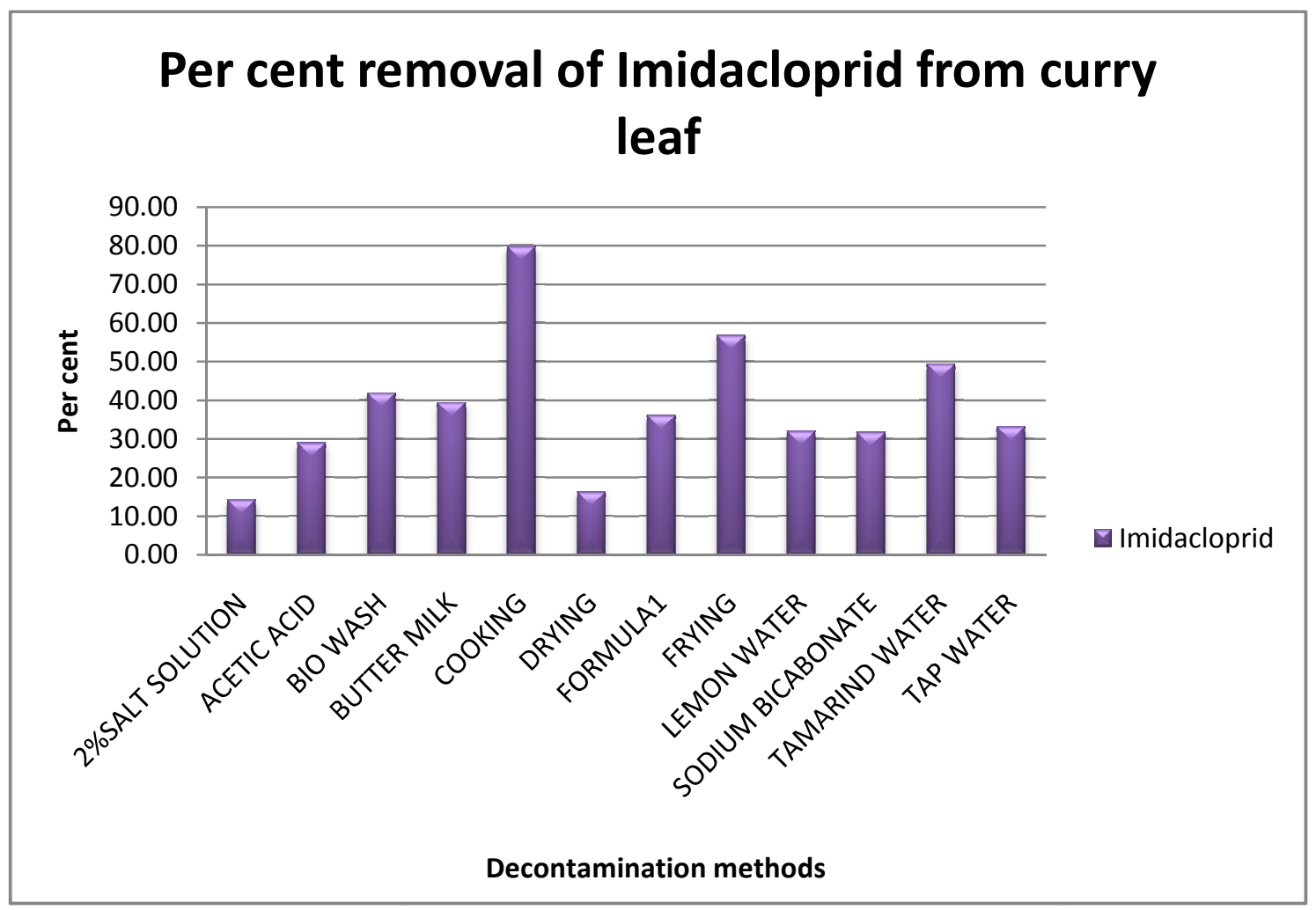

Fig. 4: Per cent removal of imidacloprid residues from curry leaf by various decontamination methods 


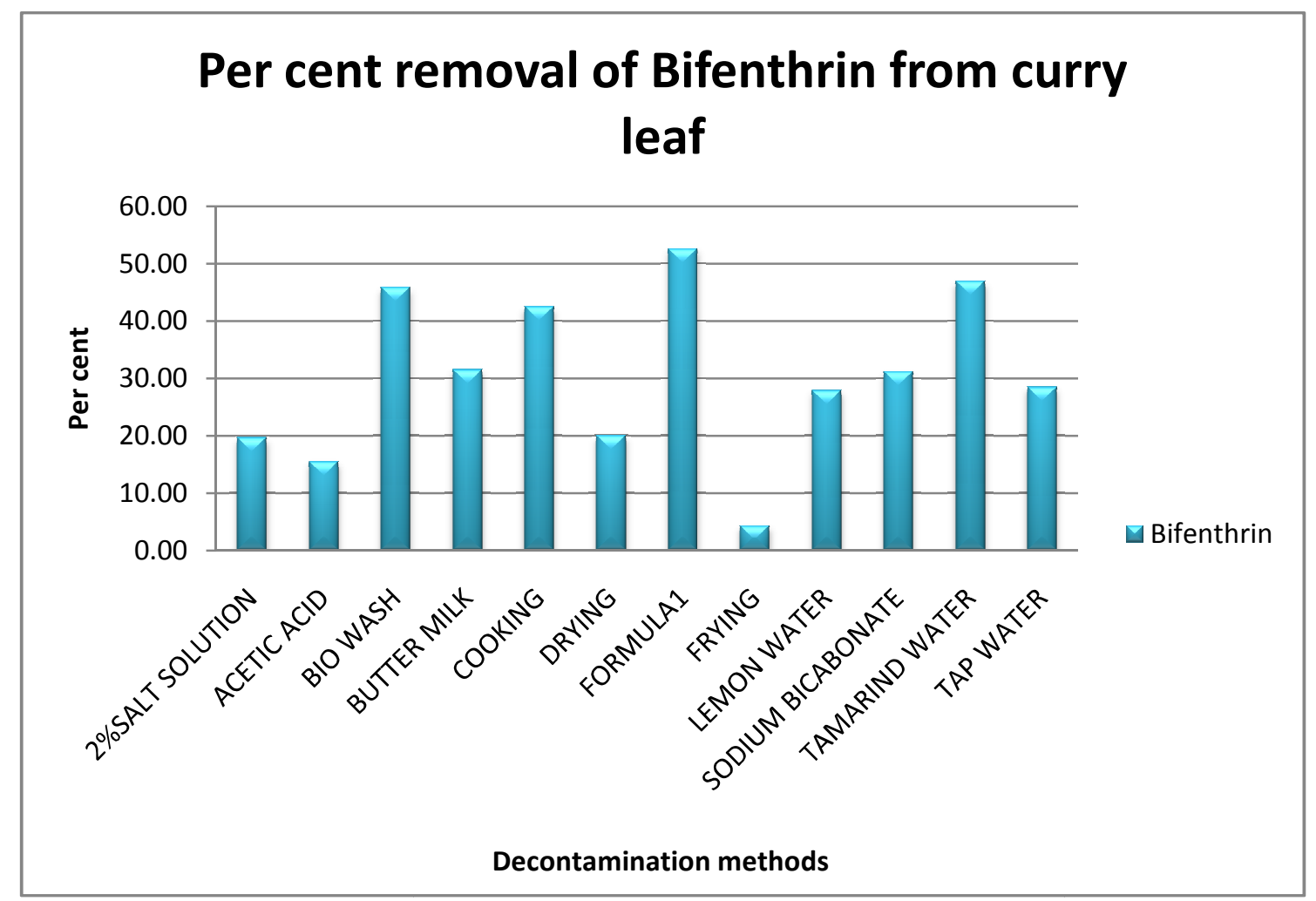

Fig. 5: Per cent removal of Bifenthrin residues from curry leaf by various decontamination methods

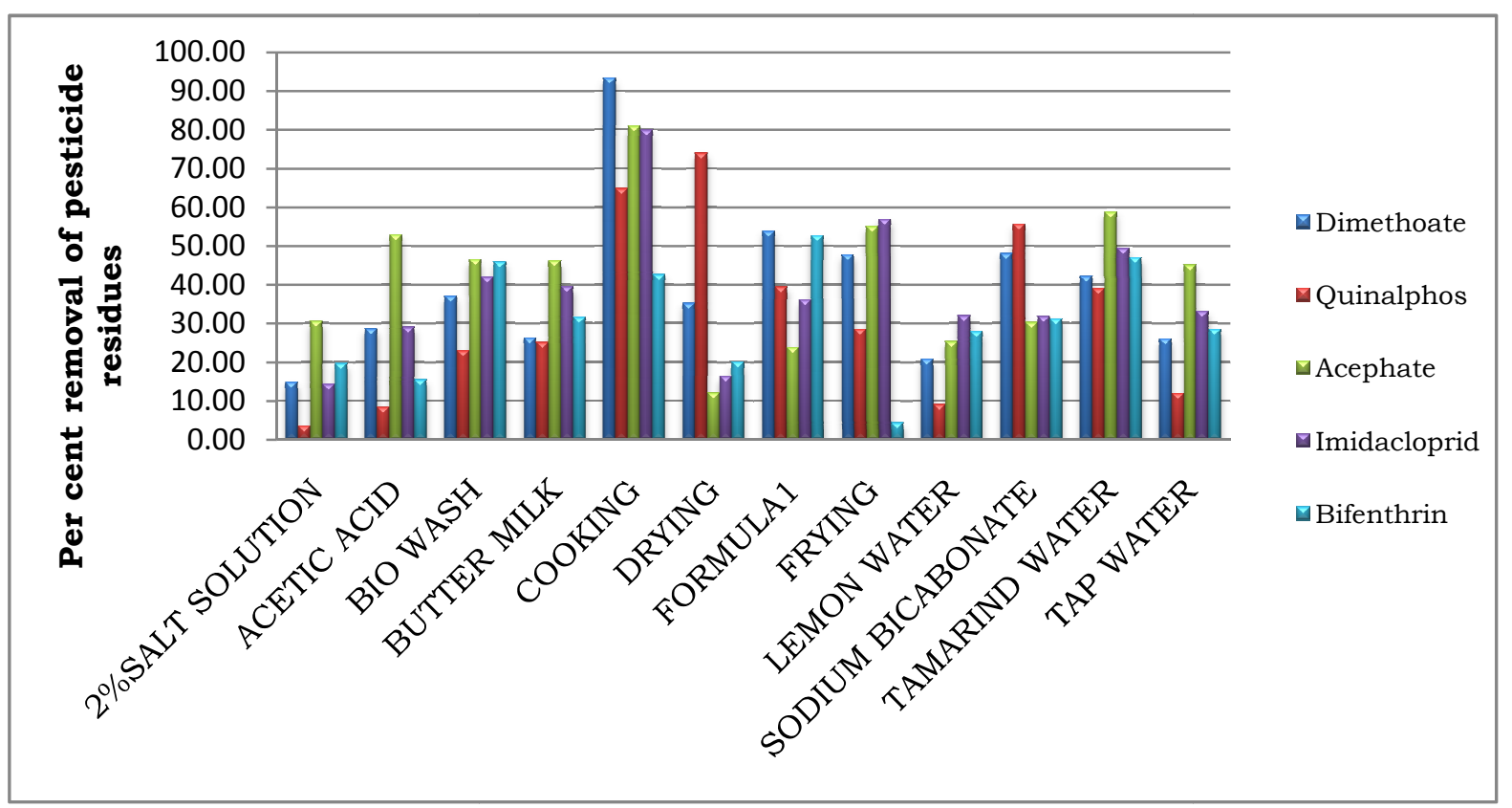

Fig. 6: Per cent removal of pesticide residues from curry leaf by various decontamination methods 